OPEN ACCESS

Edited by:

Mark Andrew Lawrence,

Deakin University, Australia

Reviewed by:

Rebecca Leigh Lindberg,

Deakin University, Australia

Maria Ewa Rembialkowska,

Warsaw University of Life Sciences,

Poland

*Correspondence:

Eric O. Verger

eric.verger@ird.fr

Marie-Josèphe Amiot

marie-josephe.amiot-carlin@inra.fr

Specialty section

This article was submitted to

Nutrition and Environmental

Sustainability,

a section of the journal

Frontiers in Nutrition

Received: 20 February 2018

Accepted: 12 April 2018

Published: 22 May 2018

Citation:

Verger EO, Perignon M, El Ati J, Darmon N, Dop M-C, Drogué S, Dury $S$, Gaillard $C$, Sinfort $C$ and Amiot M-J (2018) A "Fork-to-Farm" Multi-Scale Approach to Promote Sustainable

Food Systems for Nutrition and

Health: A Perspective for the Mediterranean Region.

Front. Nutr. 5:30.

doi: 10.3389/fnut.2018.00030

\section{A "Fork-to-Farm" Multi-Scale Approach to Promote Sustainable Food Systems for Nutrition and Health: A Perspective for the Mediterranean Region}

\author{
Eric O. Verger ${ }^{1 *}$, Marlene Perignon ${ }^{2}$, Jalila El Ati ${ }^{3}$, Nicole Darmon ${ }^{2}$, Marie-Claude Dop ${ }^{1}$, \\ Sophie Drogué ${ }^{2}$, Sandrine Dury ${ }^{2}$, Cédric Gaillard ${ }^{2}$, Carole Sinfort ${ }^{4}$, and \\ Marie-Josèphe Amiot ${ }^{2 *}$ on behalf of the MEDINA-Study Group
}

${ }^{1}$ NUTRIPASS, IRD, Univ Montpellier, SupAgro, Montpellier, France, ${ }^{2}$ MOISA, Univ Montpellier, CIHEAM-IAMM, CIRAD, INRA, Montpellier SupAgro, Montpellier, France, ${ }^{3}$ Research Laboratory SURVEN Nutritional Surveillance and Epidemiology in Tunisia, National Institute of Nutrition and Food Technology (INNTA), Tunis, Tunisia, ${ }^{4}$ ELSA Group, ITAP, SupAgro, Irstea, Univ Montpellier, Montpellier, France

Mediterranean countries are undergoing dietary and nutritional changes that affect their inhabitants' health, while facing massive environmental challenges. The increasing demand of water in agriculture, the capacity to maintain local food production, and the growing dependence on food imports are interconnected issues that must be addressed to ensure food security and nutrition in the Mediterranean region. Here, we present the conceptual framework and methodologies developed by the MEDINA-Study Group for rethinking food systems toward sustainable consumption and production modes. Based on its multidisciplinary expertise, the MEDINA-Study Group designed a "fork-to-farm" multi-scale approach, stemming from current dietary habits and examining how some options to nutritionally improve these habits might affect the food systems. This approach was developed for research activities in the South of France and Tunisia, two areas with very different diet-agriculture-environment nexus. The conceptual framework is based on the analysis of elements of the food systems (from consumption to production) at different levels (individual, household, regional and national levels). The methods include: (i) modeling options of dietary changes at different scales, in order to nutritionally optimize food consumption-production without increasing the environmental impact, (ii) translating the best-choice changes into possible policy actions, (iii) testing the acceptability and feasibility of these actions with several stakeholders, and (iv) producing guidelines for sustainable food choices and production. The MEDINA-Study Group identified additional issues that could be included in a future framework to help designing ambitious agricultural, food and health policies in the Mediterranean region.

Keywords: food system, diet, sustainability, conceptual framework, life cycle analysis, local agro-ecosytem, mathematical optimization, multi-criteria mapping 


\section{INTRODUCTION}

Food systems have long been described as chains of activities from food production ("the farm") to consumption ("the fork"), including processing, packaging, distribution and retail. These activities are influenced by many political, economic, sociocultural, and environmental factors (1). Indeed, recently, food systems have been conceptualized as complex socio-ecological systems that involve cross-level and cross-scale interactions between human and natural components and major social outcomes, such as ecosystem services, social welfare and food security (2). Food security is a situation that exists when all people, at all times, have physical, social and economic access to sufficient, safe and nutritious food that meets their dietary needs and food preferences for an active and healthy life (3).

The 2015 Food and Agriculture Organization (FAO) report on the State of Food Insecurity in the World considered that most of the Southern Europe, Middle East and North Africa countries that constitute the Mediterranean region have eradicated severe food insecurity (4). Nevertheless, the traditional Mediterranean dietary pattern has progressively declined in the last 50 years (5-7). Concomitantly, food habits in the Mediterranean countries have largely evolved with more consumption of animalbased products and ultra-processed foods, and less plant-based products, indicating a westernization of dietary patterns $(8,9)$. Populations exposed to this dietary shift are less likely to achieve adequate intakes of nutrients compared with people with greater adherence to the Mediterranean diet (10). Consequently, they are at high risk of obesity (11-13) and of other diet-related non-communicable diseases $(14,15)$. Among the whole range of determinants that have contributed to the current situation, a majority relies on the great availability and accessibility of foods typical of the Western lifestyle (highly processed, calorie-rich, nutrient-poor food and animal products). This has been facilitated by activities of transnational food corporations (e.g., food marketing and retailing systems), trade liberalization policies, and sometimes government subsidies (16).

Simultaneous to the dietary and nutritional shift, the Mediterranean region is facing massive environmental changes: land use and degradation, water scarcity, environment pollution, biodiversity loss, and climate change (17). Furthermore, recent analyses show that the current Western-style diet has a high environmental impact (18). While the Mediterranean region has been a major food-producing area with a large agro-biodiversity for millennia, environmental alterations may threaten the local food system capacities to ensure food and nutrition security (19).

Therefore, it is crucial to develop the concept and use of sustainable diets in different contexts (industrialized and transition countries) to ensure food security and quality $(20,21)$, especially in the Mediterranean region. In contrast to the "farmto-fork" approach (from production to consumption) that is commonly used to improve the food systems in terms of food safety (22) and nutrition (23), the MEDINA research project "Promoting sustainable food systems in the Mediterranean for good nutrition and health" proposes a "fork-to-farm" conceptual framework. Stemming from the current dietary habits of the Mediterranean population, this program aims to identify the dietary changes needed to ensure quantitative and qualitative food security, while examining how these changes might affect the whole food systems.

The first part of this article presents the relevant parameters to be included in this conceptual framework for rethinking food systems in order to promote sustainable consumption and production in the Mediterranean region. Then, it describes the approach and the methodologies developed by the MEDINAStudy Group to identify the dietary changes needed (i) to nutritionally optimize food consumption-production without increasing the environmental impact, and (ii) to assess the acceptability and feasibility of these changes by the various food system stakeholders. The last part presents and discusses the perspectives for implementing other relevant parameters in the initial framework.

\section{PARAMETERS AFFECTING THE SUSTAINABILITY OF FOOD SYSTEMS IN THE MEDITERRANEAN REGION}

The MEDINA-Study Group includes experts in nutrition, food science, epidemiology, biostatistics, agronomy, environmental science and economics. Based on literature review and discussions, the MEDINA-Study Group identified relevant parameters to be included in a conceptual framework to assess the sustainability of food systems in the South of France and Tunisia, two completely different areas concerning the diet-agriculture-environment nexus.

\section{Adherence to the Mediterranean Diet Pyramid}

The Mediterranean basin is the cradle of the "traditional Mediterranean diet" that is proposed as a healthy diet model to prevent coronary heart diseases (24), and has been registered by UNESCO in 2010 as an intangible heritage of humanity (25). Prospective and interventional studies in the Mediterranean region confirmed that good adherence to this dietary pattern is systematically associated with a markedly reduced risk of obesity (26), metabolic syndrome (27-29), type 2 diabetes $(30,31)$, and cardiovascular diseases $(32,33)$.

In addition, Mediterranean traditional foods contain a large diversity and quantity of micronutrients and bio-active compounds (34) and a way to meet the nutrient requirements (10). Interestingly, computer-generated personalized diets emphasize the need to increase the consumption of foods typical of the Mediterranean diet (nuts, unrefined grains, vegetables and legumes, fruit, fish, and shellfish) to fulfill the individual nutrient requirements (35). In the Mediterranean region, promoting the adherence to the Mediterranean diet pyramid (36) is relevant for ensuring good health and nutrition.

Moreover, the Mediterranean diet pyramid takes into account the local and seasonal declination of this dietary pattern around the Mediterranean border (5), as well as the associated knowhow, knowledge, practices and traditions (37). Therefore, it is important also to assess the nutritional value and nutrient profile of local products and recipes (38). 
To ensure good health and nutrition while respecting the socio-cultural context of the Mediterranean region, the adherence to the Mediterranean diet pyramid will be included in the conceptual framework as an objective of the optimization mathematical models (see section The MEDINA "Fork-to-Farm" Multi-Scale Approach).

\section{Nutritional Potential of Local Agro-Ecosystems}

In addition to the nutritional value and nutrient profile of local products and recipes, it is also important to understand the nutritional potential of local agro-ecosystems, including wild edible plants and animals that are currently neglected and underused. The potential role of domesticated and wild biodiversity in addressing food security, nutrition deficiencies and the emerging burden of non-communicable diseases was emphasized by the cross-cutting initiative on biodiversity for food and nutrition (39). Since then, it has been acknowledged that the proper management of the local domesticated and wild biodiversity significantly contributes to sustainable food systems by ensuring both human and environmental health (40). Furthermore, understanding the nutritional potential of local agro-ecosystems is a critical step when assessing how the agricultural production could contribute to the food and nutrition security inside households involved in agricultural activities. Indeed, the contribution to nutrition can be direct via self-consumption, in-kind donations and the presence of wild plants, or indirect through farm and off-farm incomes $(41,42)$.

The "nutritional potential of local agro-ecosystems" parameter will be included in the conceptual framework thanks to specific survey on agriculture and wild biodiversity in a rural region of Tunisia (see section The MEDINA "Fork-To-Farm" Multi-Scale Approach).

\section{Environmental Impacts of the Food Systems}

Many studies on the evaluation of the environmental impact of food systems use the Life Cycle Analysis (LCA) approach, a normalized method to assess all environmental impacts (43). Within the food chain, the production phase (mainly meat and dairy) has the highest impact, together with transport, packaging and food loss/waste (44). The main contributors are greenhouse gas (GHG) emissions, water deprivation, and land use for production (transformation and occupation). This causes biodiversity loss and affects soil quality, particularly the use of toxic products, mainly pesticides, in farmed soil (44).

It has been acknowledged that a better adherence to the Mediterranean diet reduces the environmental impact thanks to the consumption of more plant-derived products and fewer animal products, whereas a Western-style diet is associated with high environmental impacts (45-47). Furthermore, due to the increasing complexity of the food chain, there is a trend to have a greater flow of food commodities over long distances, and to consume highly processed and packaged foods that contribute to increase GHG emissions and deplete non-renewable resources (48). Finally, as the Mediterranean population represents $60 \%$ of the population of water-scarce countries (48), particular attention should be paid to water use.

To ensure the sustainability of the food systems in the Mediterranean region, the "environmental impacts of the food systems" parameter will be included in the conceptual framework as constraints of the optimization mathematical models (see section The MEDINA “Fork-To-Farm” Multi-Scale Approach).

\section{Food Trade and Dependence on Food Imports}

Since 1965, the importance of food trade has increased worldwide, and progressively more people are becoming dependent on food imports to ensure food availability (49). In the Mediterranean basin, France is a strong agro-food exporting country, whereas other Mediterranean countries are more and more dependent on food imports (49). Indeed, except for France, all Northern Mediterranean countries (e.g., Italy and Spain) suffered from a dramatic decline in food self-sufficiency (49).

To take into account the importance of the "food trade and dependence on food imports" parameter, the conceptual framework will include national food availability data (FAO food balance sheets) which provide information of food production but also imports and exports (see section The MEDINA "ForkTo-Farm” Multi-Scale Approach).

\section{THE MEDINA "FORK-TO-FARM" MULTI-SCALE APPROACH}

The aim of the MEDINA research project is to propose guidelines and policy actions to promote sustainable food systems for ensuring good health and nutrition for the Mediterranean populations, while mitigating the environmental impact and promoting the local cultural heritage and traditional food products.

The first step of the "fork-to-farm" multi-scale approach developed by the MEDINA-Study Group (Figure 1) is to determine the current, individual and household dietary habits and practices. This information will be used to identify the dietary changes needed to ensure food and nutrition security. The second step is to evaluate how these changes could affect food production and availability at the household, regional and national scales.

Analysis at different scales are possible by using existing datasets and by performing new surveys specifically for the MEDINA project (Figure 1). Existing food consumption datasets representative of the adult population living in the South of France (50) and Tunisia (TAHINA: Epidemiological Transition and Health Impact in North Africa-Contract Number: ICA3CT-2002-10011) will be used to define the current dietary habits and practices (individual level). A specific survey on the women's individual food intake and nutrition was carried out to determine the current dietary habits and practices in relation to agriculture and wild biodiversity in the Sidi Bouzid governorate (individual level). This Tunisian governorate is home to a population whom $73 \%$ is settled in a rural area and where $46 \%$ of active women are employed in the agriculture (51), a context which strongly differs with South of France where 


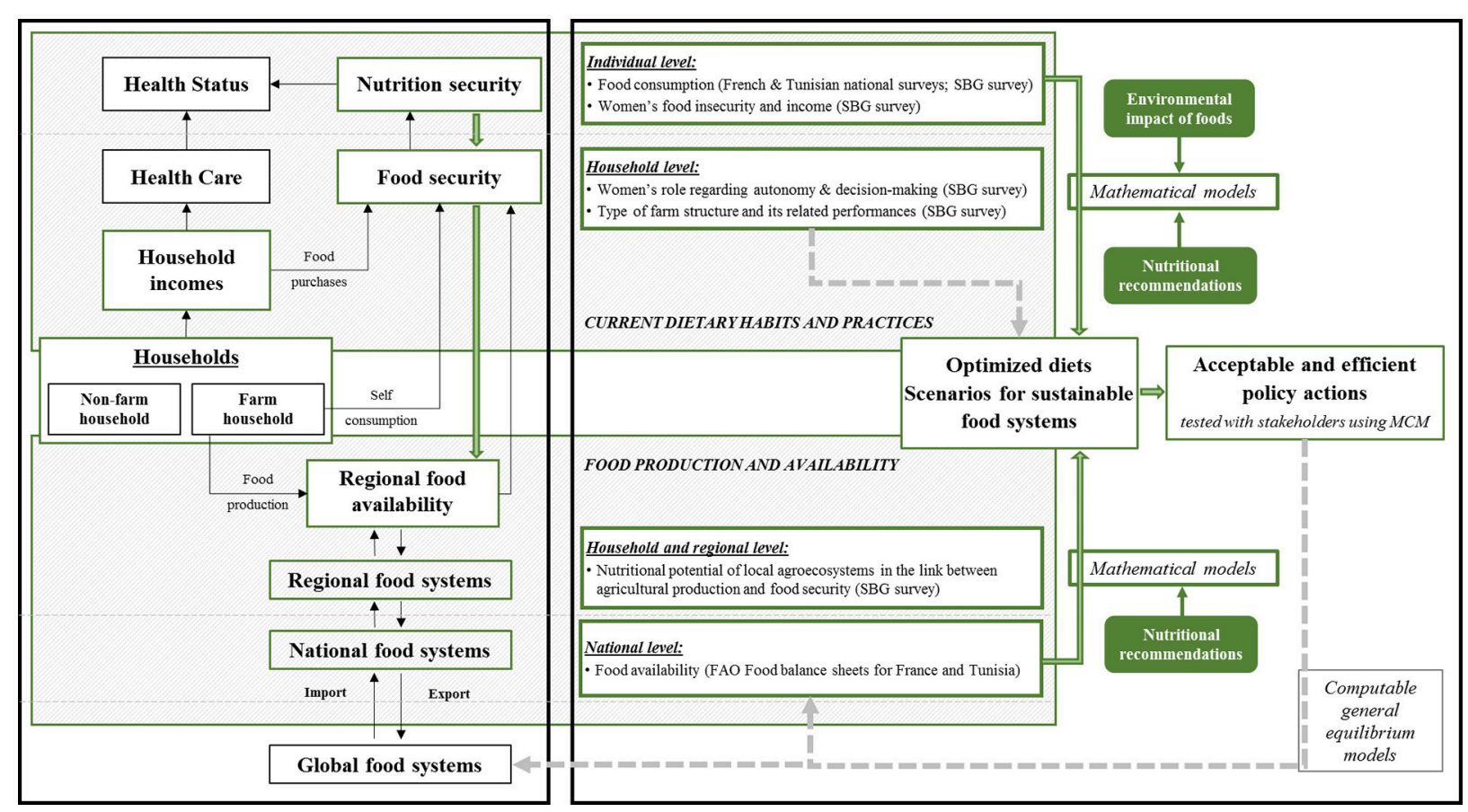

FIGURE 1 | Conceptual framework developed by the MEDINA-Study Group to provide solid support for revised guidelines compatible with sustainable food systems that promote good health and nutrition and also the local cultural heritage and traditional food products. The left side of the figure briefly summarizes how food systems, nutrition and health are interconnected and affect each other in the classical "farm-to-fork" approach (black arrows) and the "fork-to-farm" approach used in the MEDINA research project (green arrows). The right side represents the modeling approach used to propose guidelines to ensure good nutrition and sustainability, with the models currently implemented in the MEDINA research project (green arrows and boxes) and the models considered as research perspectives (gray arrows and boxes). Both sides consider different scales (individual, household, regional and national levels) by using different databases. SBG, Sidi Bouzid governorate; MCM, Multi-Criteria Mapper computer program.

agriculture concerned less than $2 \%$ of active women (52). A budget survey focused on women, their household and, where appropriate, on the farm where they live will be organized in this governorate to assess the current dietary habits and practices, farm production, and food availability (individual and household levels). This multi-level survey will allow (i) determining the farm structure types and performances, (ii) understanding the women's place and role within the farm and the household concerning autonomy and decision-making, (iii) assessing the determinants of women's food insecurity relative to their income in urban and rural situations, and (iv) integrating the nutritional potential of local agro-ecosystems in the link between agricultural production and food security within farm households. Existing data on food availability (FAO food balance sheets) for the general French and Tunisian populations will be used to define the food production and availability (national level).

To identify the dietary changes needed to reach nutritional adequacy and how these changes might affect the whole food systems, two specific models will be applied using different datasets (Figure 1). The first model will be based on the current dietary habits and practices (individual level). Specifically, the mean diet observed in the studied populations will be estimated from individual food consumption surveys. Then, mathematical models will be used to design optimized diets that fulfill the nutritional recommendations and/or the Mediterranean pyramid guidelines, while minimizing the departure from the mean diet in order to suggest realistic dietary changes. The environmental impacts (water deprivation, land use effects including biodiversity) of these optimized diets will be assessed to evaluate the compatibility between the nutritional and environmental dimensions of sustainability. More stringent models that integrate environmental constraints will be developed to design diets that fulfill the nutritional recommendations without increasing the environmental impacts (53-55).

The second model will be based on food production and availability (national level). Specifically, based on the quantities of food available for human consumption (estimated using the FAO food balance sheets), a mathematical model will be used to optimize food availability relative to nutrient requirements, while minimizing the departure from the mean diet. Then, the impacts of these changes on the food chains and general economy will be evaluated.

The different surveys and models used in the MEDINA project will provide specific outputs, such as optimized diets and scenarios for sustainable food systems. Based on these outputs, guidelines and policy actions to promote sustainable food systems for ensuring health and nutrition for the Mediterranean populations could be designed. 
One way to ensure the efficiency of the future guidelines is to involve key stakeholders during the development process. This will be done through three steps: (i) translation of the previously identified sustainable dietary changes into a range of different policy actions based on discussions within the MEDINA-Study Group; (ii) collecting, via structured interviews, the opinion of key stakeholders on the overall performance of the pre-defined policy actions. This will be done using a multicriteria mapping technique based on the "Multi-Criteria Mapper" computer program (56); and (iii) providing useful guidelines to policy-makers on sustainable food choices and production based on the policy actions that were most valued by the participant stakeholders.

Furthermore, the MEDINA framework includes analysis and models considered as research perspectives. A first perspective is the use of a spatialized analysis to assess the impact of water deprivation and land use occupation and transformation in other countries linked to the import of food (or animal feed) products. Another perspective is the use of a multi-sectoral, multi-regional computable general equilibrium (CGE) model allow to consider the complexity of the relations that link countries in a global economy, as well as the possible feedback associated with exogenous shocks.

\section{PRELIMINARY RESULTS OBTAINED FROM THE MEDINA FRAMEWORK}

The MEDINA "fork-to-farm" is a promising framework for rethinking food systems toward sustainable consumption and production modes thanks to its multi-scale approach, as illustrated by the following preliminary results obtained at individual level and national level for Tunisia.

Using the first model based on the current dietary habits and practices (individual level), we found that the main dietary changes needed to satisfy all the nutrient recommendations were the increases of fruits and dairy products, and decreases of meat and starchy foods. Nevertheless, these changes increased the environmental impacts of the diets. In a scenario where environmental indicators were limited to their observed levels, the dietary changes needed were still the decreases of meat and starchy foods but also lower increases of fruits and dairy products in favor of vegetables (57).

Using the second model based on food production and availability (national level), we found that the main changes in food availability needed to satisfy all the nutrient recommendations-without considering the environmental impacts-were the reduction of the imports of starchy foods, sugar, meat, soybean and palm oil and a moderate reduction of olive oil exports (58).

\section{RECOMMENDATIONS OF FUTURE RESEARCH AND ACTIONS}

Although the "fork-to-farm" multi-scale approach will be useful for designing relevant agricultural, food and health policies, the MEDINA-Study Group identified other factors to improve the framework.
Adhering to the Mediterranean diet pyramid seems to be relevant for ensuring good health and nutrition; however, the diet nutritional adequacy depends on the total nutrients intake and bioavailability, defined as the proportion of an ingested nutrient that is absorbed and utilized through normal metabolic pathways (59). When promoting more sustainable diets that imply a shifts from animal-based toward plant-based products, changes in nutrient bioavailability, which strongly depends on the food source (animal vs. plant) and diet composition (e.g., iron, zinc, protein, and vitamin A), should be assessed and integrated in the future design of optimized diets (60).

Another relevant aspect for ensuring good health and nutrition concerns the assessment of the chemicals used in agriculture to increase the efficiency and yield (fertilizers, pesticides, hormones, antibiotics). The general population could be exposed to pesticides by ingestion of food and drinking water. Moreover, specific populations, such as farmers and farm workers, could also be directly exposed by dermal contact or inhalation $(61,62)$. Many studies have documented how pesticide exposure can negatively affect health, being related to various diseases including cancers, leukemia and asthma (52). Future research should address this point, with a holistic methodology that takes into account the exposures to dietary contaminants when respecting nutrient recommendations (63), but also production efficiency and yield.

In their modeling study, Tilman et al. stressed the importance of assessing the impact of consumption changes on the environment, particularly GHG emissions, water deprivation and land use (land clearing and habitat fragmentation, soil quality (64)). Agriculture has an important role to play in reducing GHG emissions, decreasing fossil energy consumption, optimizing the nitrogen life cycle to limit nitrogen inputs, enhancing soil carbon sequestration, and improving the use of manure and slurry. Future research should adopt a global comprehensive approach to evaluate the sustainability of these trade balances which is necessary for the survival of agriculture in most countries at risk (65).

Behind the "fork-to-farm" approach there is also the idea that in a globalized economy, aggregated individual decisions affect also the global economy. This is the case when dietary habits change at the country level. To assess the possible outcome of dietary recommendations, we need models that can reproduce the relationships between domestic demand and supply in the agricultural sector, and between agriculture and the rest of the economy. These models must also summarize the links between a country and the rest of the world through trade. Future research should integrate CGE models like the Global Trade Analysis Project (GTAP) model maintained by the University of Purdue which allows simulating the scenarios of change (66), built from the results of the optimization models at the individual and aggregated levels. The GTAP approach allows going back-andforth between various scale levels.

While the specific optimization models used in the MEDINA project focus on the individual and national levels, future work should concern the regional level. Moreover, if the resulting scenarios provide the basis for actions and discussions with policy-makers and agro-food chain stakeholders, the next step will be to work on the pathways from current consumption, 
agricultural production and agro-food chain organization toward the future sustainable scenarios.

\section{CONCLUSION}

To promote sustainable food systems for nutrition and health in the Mediterranean region, the MEDINA-Study Group developed a conceptual framework and methodologies for rethinking food systems. The group also identified additional issues that can be included in the initial framework, such as nutrient bioavailability and exposure to contaminants and active substances used in agriculture, and that could contribute to the design of ambitious agricultural, food and health policies and to action prioritization.

\section{AUTHOR CONTRIBUTIONS}

$\mathrm{EV}, \mathrm{MP}$, and M-JA wrote the first draft of the manuscript; JE, $\mathrm{ND}, \mathrm{M}-\mathrm{CD}$, SoD, SaD, CG, and CS contributed to writing the manuscript and offered critical comments; and all authors read and approved the final manuscript.

\section{ACKNOWLEDGMENTS}

This work was supported by the Agence Nationale de la Recherche (France) as part of the MEDINA research project

\section{REFERENCES}

1. Sobal J, Khan LK, Bisogni C. A conceptual model of the food and nutrition system. Soc Sci Med. (1998) 47:853-63.

2. Ericksen PJ. Conceptualizing food systems for global environmental change research. Glob Environ Change (2008) 18:234-45. doi: 10.1016/j.gloenvcha.2007.09.002

3. FAO. The State of Food Insecurity in the World 2001. Rome: FAO (2002).

4. FAO, IFAD and WFP. The State of Food Insecurity in the World 2015, Meeting the 2015 International Hunger Targets: Taking Stock of Uneven Progress. Rome: FAO (2015).

5. da Silva R, Bach-Faig A, Raidó Quintana B, Buckland G, Vaz de Almeida MD, Serra-Majem L. Worldwide variation of adherence to the Mediterranean diet, in 1961-1965 and 2000-2003. Public Health Nutr. (2009) 12:1676-84. doi: 10.1017/S1368980009990541

6. Kontogianni MD, Vidra N, Farmaki A-E, Koinaki S, Belogianni K, Sofrona S, et al. Adherence rates to the Mediterranean diet are low in a representative sample of Greek children and adolescents. J Nutr. (2008) 138:1951-6. doi: $10.1093 /$ jn/138.10.1951

7. León-Muñoz LM, Guallar-Castillón P, Graciani A, López-García E, Mesas AE, Aguilera MT, et al. Adherence to the Mediterranean diet pattern has declined in Spanish adults. J Nutr. (2012) 142:1843-50. doi: 10.3945/jn.112. 164616

8. Aounallah-Skhiri H, Traissac P, El Ati J, Eymard-Duvernay S, Landais E, Achour N, et al. Nutrition transition among adolescents of a southMediterranean country: dietary patterns, association with socio-economic factors, overweight and blood pressure. A cross-sectional study in Tunisia. Nutr J. (2011) 10:38. doi: 10.1186/1475-2891-10-38

9. Mehio Sibai A, Nasreddine L, Mokdad AH, Adra N, Tabet M, Hwalla N. Nutrition transition and cardiovascular disease risk factors in Middle East and North Africa countries: reviewing the evidence. Ann Nutr Metab. (2010) 57:193-203. doi: 10.1159/000321527

10. Castro-Quezada I, Román-Viñas B, Serra-Majem L. The mediterranean diet and nutritional adequacy: a review. Nutrients (2014) 6:231-48. doi: $10.3390 /$ nu6010231
Promoting sustainable food systems in the Mediterranean for good nutrition and health (ANR-12-TMED-0004-01); INNTA (Tunisian National Institute of Nutrition and Food Technology); and Bioversity International.

This work has been presented as a poster in October 2017 at the 21st International Congress of Nutrition in Buenos Aires, Argentina, and which the abstract has been published in a supplemental issue of Annals of Nutrition and Metabolism (doi: 10.1159/000480486).

The MEDINA-Study Group: M-JA (Chair, INRA, France), Nawel Achir (CIRAD, France), Leila Alouane (INNTA, Tunisia) JE (INNTA, Tunisia), Sihem Bellagha (INAT, Tunisia), PierreMarie Bosc (CIRAD, France and FAO, Italy), Mélanie Broin (Agropolis, France), ND (INRA, France), Claudie DhuiqueMeyer (CIRAD, France), M-CD (IRD, France), SoD (INRA, France), $\mathrm{SaD}$ (CIRAD, France), Ahmed Ferchoui (INRA, France), CG (CIRAD, France), Zeineb Ghrabi (INAT), Florence Jacquet (INRA, France), Yves Kameli (IRD, France), Fayçal Kefi (CIHEAM, France/Italy), Faten Khamassi (INAT, Tunisia), Emmanuelle Kesse-Guyot (INRA, France), Denis Lairon (INSERM, France), Yves Martin-Prevel (IRD, France), Caroline Méjean (INRA, France), Claire Mouquet-Rivier (IRD, France), Sondos Njoumi (INAT, Tunisia), Martine Padilla (CIHEAM, France), MP (INRA, France), CS (SupAgro, France), Pierre Traissac (IRD, France), EV (IRD, France).

11. Issa C, Darmon N, Salameh P, Maillot M, Batal M, Lairon D. A Mediterranean diet pattern with low consumption of liquid sweets and refined cereals is negatively associated with adiposity in adults from rural Lebanon. Int J Obes. (2011) 35:251-8. doi: 10.1038/ijo.2010.130

12. Panagiotakos DB, Chrysohoou C, Pitsavos C, Stefanadis C. Association between the prevalence of obesity and adherence to the Mediterranean diet: the ATTICA study. Nutr Burbank Los Angel Cty Calif. (2006) 22:449-56. doi: 10.1016/j.nut.2005.11.004

13. Schröder H, Marrugat J, Vila J, Covas MI, Elosua R. Adherence to the traditional mediterranean diet is inversely associated with body mass index and obesity in a spanish population. J Nutr. (2004) 134:3355-61. doi: $10.1093 /$ jn/134.12.3355

14. Filippatos TD, Panagiotakos DB, Georgousopoulou EN, Pitaraki E, Kouli G-M, Chrysohoou C, et al. Mediterranean diet and 10-year (20022012) incidence of diabetes and cardiovascular disease in participants with prediabetes: the ATTICA study. Rev Diabet Stud. (2016) 13:226-35. doi: 10.1900/RDS.2016.13.226

15. Salas-Salvadó J, Bulló M, Estruch R, Ros E, Covas M-I, Ibarrola-Jurado N, et al. Prevention of diabetes with Mediterranean diets: a subgroup analysis of a randomized trial. Ann Intern Med. (2014) 160:1-10. doi: 10.7326/M13-1725

16. Kearney J. Food consumption trends and drivers. Philos Trans R Soc Lond B Biol Sci. (2010) 365:2793-807. doi: 10.1098/rstb.2010.0149

17. Thiébault S, Moatti J-P. The Mediterranean Region under Climate Change: $A$ Scientific Update. Marseille: IRD Éditions/AllEnvi (2016).

18. Lacirignola C, Capone R, Debs P, El Bilali H, Bottalico F. Natural resources - food nexus: food-related environmental footprints in the mediterranean countries. Front Nutr. (2014) 1:23. doi: 10.3389/fnut.2014.00023

19. Myers SS, Smith MR, Guth S, Golden CD, Vaitla B, Mueller ND, et al. Climate change and global food systems: potential impacts on food security and undernutrition. Annu Rev Public Health (2017) 38:259-77. doi: 10.1146/annurev-publhealth-031816-044356

20. Meybeck A, Gitz V. Sustainable diets within sustainable food systems. Proc Nutr Soc. (2017) 76:1-11. doi: 10.1017/S0029665116000653

21. Nelson ME, Hamm MW, Hu FB, Abrams SA, Griffin TS. Alignment of Healthy Dietary Patterns and Environmental Sustainability: a Systematic 
Review. Adv Nutr Bethesda Md. (2016) 7:1005-25. doi: 10.3945/an.116. 012567

22. Scheule B, Sneed J. From Farm to Fork. J Nutr Recipe Menu Dev. (2001) 3:3-23. doi: 10.1300/J071v03n02_02

23. Vanamala J. Food systems approach to cancer prevention. Crit Rev Food Sci Nutr. (2017) 57:2573-88. doi: 10.1080/10408398.2015.1028023

24. Menotti A, Keys A, Aravanis C, Blackburn H, Dontas A, Fidanza F, et al. Seven Countries Study. First 20-year mortality data in 12 cohorts of six countries. Ann Med. (1989) 21:175-9. doi: 10.3109/07853898909149929

25. UNESCO. Evaluation of Nominations for Inscription in 2010 on the Representative List of the Intangible Cultural Heritage of Humanity. Fifth Session, 15-19 of November 2010, Nairobi Kenya (2010).

26. Beunza J-J, Toledo E, Hu FB, Bes-Rastrollo M, Serrano-Martínez M, Sánchez-Villegas A, et al. Adherence to the Mediterranean diet, longterm weight change, and incident overweight or obesity: the Seguimiento Universidad de Navarra (SUN) cohort. Am J Clin Nutr. (2010) 92:1484-93. doi: 10.3945/ajcn.2010.29764

27. Babio N, Toledo E, Estruch R, Ros E, Martínez-González MA, Castañer $\mathrm{O}$, et al. Mediterranean diets and metabolic syndrome status in the PREDIMED randomized trial. Can Med Assoc J. (2014) 186:E649-57. doi: 10.1503/cmaj.140764

28. Kesse-Guyot E, Ahluwalia N, Lassale C, Hercberg S, Fezeu L, Lairon D. Adherence to Mediterranean diet reduces the risk of metabolic syndrome: a 6-year prospective study. Nutr Metab Cardiovasc Dis. (2013) 23(7):677-83. doi: 10.1016/j.numecd.2012.02.005

29. Mayneris-Perxachs J, Sala-Vila A, Chisaguano M, Castellote AI, Estruch $\mathrm{R}$, Covas MI, et al. Effects of 1-year intervention with a mediterranean diet on plasma fatty acid composition and metabolic syndrome in a population at high cardiovascular risk. PLoS ONE (2014) 9:e85202. doi: 10.1371/journal.pone.0085202

30. Romaguera D, Norat T, Vergnaud A-C, Mouw T, May AM, Agudo A, et al. Mediterranean dietary patterns and prospective weight change in participants of the EPIC-PANACEA project. Am J Clin Nutr. (2010) 92:912-21. doi: 10.3945/ajen.2010.29482

31. Salas-Salvadó J, Bulló M, Babio N, Martínez-González MÁ, Ibarrola-Jurado $\mathrm{N}$, Basora J, et al. Reduction in the incidence of type 2 diabetes with the Mediterranean diet: results of the PREDIMED-Reus nutrition intervention randomized trial. Diabetes Care (2011) 34:14-9. doi: 10.2337/dc10-1288

32. Rees K, Hartley L, Flowers N, Clarke A, Hooper L, Thorogood M, et al. "Mediterranean" dietary pattern for the primary prevention of cardiovascular disease. Cochrane Database Syst Rev. (2013) 12:CD009825. doi: 10.1002/14651858.CD009825.pub2

33. Sofi F, Macchi C, Abbate R, Gensini GF, Casini A. Mediterranean diet and health status: an updated meta-analysis and a proposal for a literature-based adherence score. Public Health Nutr. (2014) 17:2769-82. doi: $10.1017 / S 1368980013003169$

34. Gerber M. Biofactors in the Mediterranean diet. Clin Chem Lab Med. (2003) 41(8):999-1004. doi: 10.1515/CCLM.2003.153

35. Maillot M, Issa C, Vieux F, Lairon D, Darmon N. The shortest way to reach nutritional goals is to adopt Mediterranean food choices: evidence from computer-generated personalized diets. Am J Clin Nutr. (2011) 94:1127-37. doi: 10.3945/ajcn.111.016501

36. Bach-Faig A, Berry EM, Lairon D, Reguant J, Trichopoulou A, Dernini S, et al. Mediterranean diet pyramid today. Science and cultural updates. Public Health Nutr. (2011) 14:2274-84. doi: 10.1017/S1368980011002515

37. Dernini S. The erosion and the renaissance of the Mediterranean diet: a sustainable cultural resource. Quad Mediterrania IEMED Barc. (2011) 16:75-82.

38. Issa C, Salameh P, Batal M, Vieux F, Lairon D, Darmon N. The nutrient profile of traditional Lebanese composite dishes: comparison with composite dishes consumed in France. Int J Food Sci Nutr. (2009) 60(Suppl. 4):285-95. doi: 10.1080/09637480903107700

39. CBD/UNEP. Framework for a Cross-cutting Initiative on Biodiversity for Food and Nutrition, Decision VIII/23A, 8th Conference of the Parties of the Convention on Biological Diversity, Curitiba, Brazil (2006).

40. Heywood V. Overview of agricultural biodiversity and its contribution to nutrition and health. In: Fanzo J, Hunter D, Borelli T, Mattei, F, editors,
Diversifying Food and Diets: Using Agricultural Biodiversity to Improve Nutrition and Health. London; New York, NY: Routledge (2013). p. 35-67.

41. Kadiyala S, Harris J, Headey D, Yosef S, Gillespie S. Agriculture and nutrition in India: mapping evidence to pathways. Ann NY Acad Sci. (2014) 1331(1):4356. doi: $10.1111 /$ nyas. 12477

42. Powell B, Thilsted SH, Ickowitz A, Termote C, Sunderland T, Herforth A. Improving diets with wild and cultivated biodiversity from across the landscape. Food Secur. (2015) 7:535. doi: 10.1007/s12571-015-0466-5

43. ISO. Environmental Management - Life cycle assessment - Principles and framework, Vol. ISO 14040. International Organization for Standardization (2006). p. 1-20.

44. Garnett T. Three perspectives on sustainable food security: efficiency, demand restraint, food system transformation. What role for life cycle assessment? J Clean Prod. (2014) 73:10-8. doi: 10.1016/j.jclepro.2013.07.045

45. Castañé S, Antón A. Assessment of the nutritional quality and environmental impact of two food diets: A Mediterranean and a vegan diet. J Clean Prod. (2017) 167:929-7. doi: 10.1016/j.jclepro.2017.04.121

46. Sáez-Almendros S, Obrador B, Bach-Faig A, Serra-Majem L. Environmental footprints of Mediterranean versus Western dietary patterns: beyond the health benefits of the Mediterranean diet. Environ Health (2013) 12:118. doi: 10.1186/1476-069X-12-118

47. Vanham D, del Pozo S, Pekcan AG, Keinan-Boker L, Trichopoulou A, Gawlik BM. Water consumption related to different diets in Mediterranean cities. Sci Total Environ. (2016) 573:96-105. doi: 10.1016/j.scitotenv.2016.08.111

48. Padilla M., Capone R., Palma G. Sustainability of the food chain from field to plate: the case of the Mediterranean diet. In: Burlingame B, Dernini S, editors, Sustainable Diets and Biodiversity: Directions and Solutions for Policy, Research and Action. Proceedings of the International Scientific Symposium "Biodiversity and Sustainable Diets - United Against Hunger", 3-5 November 2010, FAO Headquarters, Rome. Rome: FAO (2012). p. 230-40.

49. Porkka M, Kummu M, Siebert S, Varis O. From food insufficiency towards trade dependency: a historical analysis of global food availability. PLoS ONE (2013) 8:e82714. doi: 10.1371/journal.pone.0082714

50. Agence Française de Sécurité Sanitaire des Aliments. Summary of the report of the 2006/2007 Individual and National Survey on Food Consumption 2 (INCA 2). Maisons-Alfort: AFSSA (2009).

51. Institut National de la Statistique. Recensement Général de la Population et de l'Habitat. Tunis: INS (2014).

52. Institut National de la Statistique et des Etudes Economiques. Tableaux de l'Économie Française. Paris: INSEE (2016).

53. Macdiarmid JI, Kyle J, Horgan GW, Loe J, Fyfe C, Johnstone A, et al. Sustainable diets for the future: Can we contribute to reducing greenhouse gas emissions by eating a healthy diet? Am J Clin Nutr. (2012) 96:632-9. doi: $10.3945 /$ ajen.112.038729

54. Milner J, Joy EJM, Green R, Harris F, Aleksandrowicz L, Agrawal S, et al. Projected health effects of realistic dietary changes to address freshwater constraints in India: a modelling study. Lancet Planet Health (2017) 1:e26-32. doi: 10.1016/S2542-5196(17)30001-3

55. Perignon M, Masset G, Ferrari G, Barré T, Vieux F, Maillot M, et al. How low can dietary greenhouse gas emissions be reduced without impairing nutritional adequacy, affordability and acceptability of the diet? A modelling study to guide sustainable food choices. Public Health Nutr. (2016) 19:2662-74. doi: 10.1017/S1368980016000653

56. Holdsworth M, El Ati J, Bour A, Kameli Y, Derouiche A, Millstone E, et al. Developing national obesity policy in middle-income countries: a case study from North Africa. Health Policy Plan (2013) 28:858-70. doi: 10.1093/heapol/czs125

57. Perignon M, El Ati J, Sinfort C, Drogué S, Darmon N, Amiot MJ. Which dietary changes to move towards nutritionally adequate diets without increasing their impact on biodiversity, water and land-use? The case of Tunisia. In: IUNS. 21st International Congress of Nutrition. Buenos Aires, Argentina, October 15-20, 2017: Abstracts. Ann Nutr Metab. (2017) 71(Suppl. 2):1-1433. doi: $10.1159 / 000480486$

58. Amiot MJ, Drogué S, Vignes R. Impact of optimized diet patterns at a macrolevel: the case of Tunisia. In: 12th European Nutrition Conference (FENS), Berlin, Germany, October 20-23, 2015: Abstracts. Ann Nutr Metab. (2015) 67(Suppl 1.):1-601. doi: 10.1159/000440895 
59. Gibson RS. The Role of diet- and host-related factors in nutrient bioavailability and thus in nutrient-based dietary requirement estimates. Food Nutr Bull. (2007) 28:S77-100. doi: 10.1177/15648265070281S108

60. Perignon M, Barré T, Gazan R, Amiot M-J, Darmon N. The bioavailability of iron, zinc, protein and vitamin $\mathrm{A}$ is highly variable in French individual diets: Impact on nutrient inadequacy assessment and relation with the animal-to-plant ratio of diets. Food Chem. (2016) 238:73-81. doi: 10.1016/j.foodchem.2016.12.070

61. Fantke P, Juraske R, Antón A, Friedrich R, Jolliet O. Dynamic multicrop model to characterize impacts of pesticides in food. Environ Sci Technol. (2011) 45:8842-9. doi: 10.1021/es201989d

62. Kim K-H, Kabir E, Jahan SA. Exposure to pesticides and the associated human health effects. Sci Total Environ. (2017) 575:525-35. doi: 10.1016/j.scitotenv.2016.09.009

63. Barré T, Vieux F, Perignon M, Cravedi J-P, Amiot M-J, Micard V, et al. Reaching nutritional adequacy does not necessarily increase exposure to food contaminants: evidence from a whole-diet modeling approach. J Nutr. (2016) 146:2149-57. doi: 10.3945/jn.116.234294

64. Tilman D, Balzer C, Hill J, Befort BL. Global food demand and the sustainable intensification of agriculture. Proc Natl Acad Sci USA. (2011) 108:20260-4. doi: $10.1073 /$ pnas. 1116437108
65. FAO. The State of the World's Land and Water Resources for Food and Agriculture (SOLAW) - Managing Systems at Risk. London: Food and Agriculture Organization of the United Nations, Rome and Earthscan (2011).

66. Corong EL, Hertel TW, McDougall R, Tsigas ME, van der Mensbrugghe D. The Standard GTAP Model, Version 7. J Glob Econ Anal. (2017) 2(1):1-119. doi: 10.21642/JGEA.020101AF

Conflict of Interest Statement: The authors declare that the research was conducted in the absence of any commercial or financial relationships that could be construed as a potential conflict of interest.

The reviewer RL and handling Editor declared their shared affiliation.

Copyright (C) 2018 Verger, Perignon, El Ati, Darmon, Dop, Drogué, Dury, Gaillard, Sinfort, and Amiot. This is an open-access article distributed under the terms of the Creative Commons Attribution License (CC BY). The use, distribution or reproduction in other forums is permitted, provided the original author(s) and the copyright owner are credited and that the original publication in this journal is cited, in accordance with accepted academic practice. No use, distribution or reproduction is permitted which does not comply with these terms. 